\title{
A Clinical Study of Micronized Acellular Dermal Matrix Collagen Paste Application with Negative Pressure Wound Therapy
}

\author{
Seung Ki Ahn, Hwan Jun Choi, Jun Beom Lee, Jun Hyuk Kim \\ Department of Plastic and Reconstructive Surgery, Soonchunhyang University College of Medicine, Cheonan, Korea
}

\begin{abstract}
Introduction: Micronized cadaveric acellular dermal matrix (mADM) paste, which functions by filling vertical wound planes with acellular dermal matrix particles and gelatin suspension, is a novel option for the treatment of hard-to-heal wounds. We aimed to evaluate the clinical outcome of mADM paste used in conjunction with negative pressure wound therapy (NPWT) in the treatment of hard-to-heal wounds.

Methods: This prospective clinical trial enrolled 20 patients with hard-to-heal wounds from January 2016 to January 2017. Wound healing was assessed at 1, 2, 3, and 4 weeks after treatment. Wound size and depth and patient satisfaction were recorded at each follow-up.

Results: The area of the wound was measured in all study participants, which decreased from an average of $15.48 \pm 22.38 \mathrm{~cm}^{2}$ at the start of the study to $8.97 \pm 17.73 \mathrm{~cm}^{2}$ after 4 weeks, with a reduction rate of $59.10 \% \pm 31.76 \%$ $(\mathrm{P}<0.0001)$. Two weeks into the study, there was a significant decline in the wound depth compared with the previous week.

Conclusion: mADM with NPWT provides effective wound healing. It is more comfortable for the patients and less timeconsuming for the nursing staff; thus, this treatment deserves a prominent place in the care of patients with hard-toheal wounds.
\end{abstract}

Keywords: Negative-pressure wound therapy; CG Paste; Acellular dermal matrix; Pressure sore

\section{Introduction}

Micronized cadaveric acellular dermal matrix (mADM) is a novel option for the treatment of chronic wounds. It can be manufactured into a highly versatile implant of paste-like consistency by mixing with a gelatin suspension, which can easily fill vertical wound planes and cavities for many applications, making it ideal to use with negative pressure wound therapy (NPWT). NPWT, also known as vacuum-assisted closure, utilizes topical negative pressure, a relatively new concept [1]. The range of indications for NPWT is constantly expanding. Indications include pressure sores, stasis ulcers, chronic hard-to-heal wounds such as diabetic foot ulcers, posttraumatic, and postoperative wounds

For implanted mADM to produce successful results, cell ingrowth and revascularization are essential, however sometimes these processes are not sufficient for mADM integration and wound healing [2]. The authors hypothesized that if chronic wounds were treated by using mADM collagen paste with NPWT, this would create a synergy effect, improving the outcome of $\mathrm{mADM}$ application and thereby increasing the speed of healing in the wound. We aimed to evaluate the clinical outcome of mADM paste with NPWT in the treatment of hard-to-heal wounds. Hard-to-heal wounds are
Original Article

Received: November 26, 2018

Revised: February 22, 2019

Accepted: February 23, 2019

Corresponding author:

Hwan Jun Choi, M.D., Ph.D.

Department of Plastic and Reconstructive Surgery, Soonchunhyang University College of Medicine, 44 Suncheonhyang 4-gil, Dongnamgu, Cheonan 31151, Korea

Tel: +82-41-570-2195

Fax: +82-41-574-6133

E-mail: medi619@hanmail.net

This work was supported by Soonchunhyang University Research Fund.

This is an Open Access article distributed under the terms of the Creative Commons Attribution Non-Commercial License (http://creativecommons.org/licenses/by-nc/4.0/) which permits unrestricted non-commercial use, distribution, and reproduction in any medium, provided the original work is properly cited.

(c) 2019 Korean Wound Management Society 
lesions that do not follow the normal processes of repair and hence heal more slowly than acute wounds. A well-established practical and predictive measure of complete wound healing over the longer term (24 weeks) is percentage of change in the wound area over the first 4 weeks [3]. This paper reports the results from the initial 20 patients enrolled in a prospective observational clinical trial.

\section{Methods}

The study was approved by the Institutional Review Board of Soonchunhyang University Hospital (IRB No. 2015-10-026) and all patients provided written informed consent before enrolling. The study was designed as a prospective clinical trial to evaluate the efficacy of mADM paste (CG Paste; Daewoong Pharmaceutical, Seoul, Korea) used together with NPWT (CuraVAC; Daewoong Pharmaceutical) in hard-to-heal wounds. From January 2016 to January 2017, 20 patients (age range, 44-82 years) with hard-to-heal wounds were enrolled in this clinical trial. Three patients had wounds on their sacral area, two had wounds on their upper extremities, five had wounds on their lower extremities except on the foot, and 10 had wounds on their feet. These were all chronic non-healing wounds with more than 1 month's duration. All wounds were normally treated for a month before this clinical study began, and proper debridement was implemented if there was a necrotizing wound. Patients who had a healing rate of less than $20 \%$ after a month of treatment were included in this study.

Each participants' liver and kidney function, glycemic control, neuropathy, and ankle-brachial index was evaluated before beginning the trial. Exclusion criteria were untreated cellulitis, malignancy, liver and kidney dysfunction, autoimmune and hematologic diseases, and history of treatment with corticosteroids, growth factors, or hyperbaric oxygen therapy within 30 days before or during the study period.

All participants were inpatients, replacement of NPWT was performed twice a week, and wound measurements were made once a week. One to three milliliters of $\mathrm{mADM}$ paste was applied once every week according to the size of the wound. Wound healing was assessed at 1,2,3, and 4 weeks after treatment. Wound size and depth and patient satisfaction were recorded at each follow-up using scored survey and adverse events were monitored throughout the follow-up. Vital signs and C-reactive protein (CRP) levels were also recorded weekly.

The primary outcome measures were as follows: woundhealing time, change in wound surface, pain, total cost, and time invested by the medical and nursing staff. Secondary outcome measures were adverse effects and comfort, and also included hematoma and seroma occurrence rates and reoperation rates. Wound-healing time was calculated from the date of initial debridement to the date of reaching an endpoint. An endpoint was a completely granulated wound, a wound ready for skin grafting, or healing by secondary intention.

The wound surface area and depth were calculated by measuring the longest horizontal axis, the longest vertical axis perpendicular to the horizontal axis with a flexible ruler, and the deepest height. After each measurement, the results were obtained according to Xakellis and Frantz method, using the following formula [4]:

Wound surface area $=$ length $\times$ width $\times 0.783$.

The level of significance was set at $5 \%$ for all analyses. Using descriptive statistics, the number of examinees, mean, standard deviation, median value, minimum value, and maximum value were the variables in the first effectiveness test analysis. Differences among baseline and post-treatment for mean wound area and wound depth were determined by paired $t$ test or Wilcoxon signed-rank test. If there were missing data regarding wound depth at each point, the value from the previous observation was carried forward (last observation carried forward).

\section{Case 1}

A 57-year-old man presented with a third-degree contact burn, chronic osteomyelitis, and joint exposure on his right foot (Fig. 1A). He was previously diagnosed with diabetes and hypertension as well as chronic venous insufficiency and uncontrolled hyperglycemia. Initially, he underwent aggressive and accurate debridement with marginal excision and removal of debris from the joint space until dirty granulation tissue no longer formed. Then, mADM paste was applied to the wound surface followed by a silicone barrier (Mepitel One; Mölnlycke Health Care, Gothenburg, Sweden) and NPWT with 80 $\mathrm{mmHg}$ pressure. The wound healed without additional surgical management within 4 weeks (Fig. 1B).

\section{Case 2}

A 73 -year-old man presented with a $9.9 \times 7.0-\mathrm{cm}$ grade IV pressure sore on the sacral area. He also had Parkinson disease and a suffered a previous cerebral infarction, was bed-ridden and in poor general health. After initial aggressive debridement $\mathrm{mADM}$ paste was applied to the wound surface and covered with a silicone barrier. NPWT with low pressure (75 

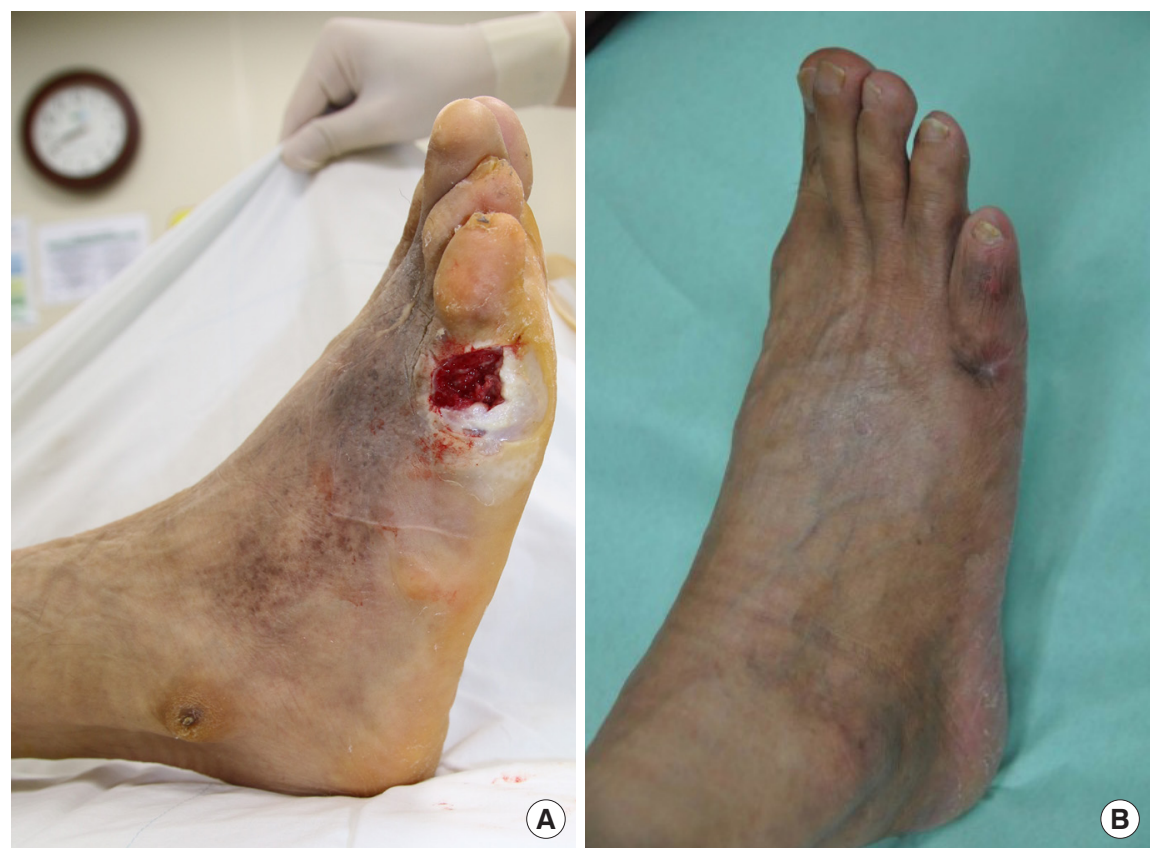

Fig. 1. Case 1. (A) A 57-year-old man presented with a third-degree contact burn, chronic osteomyelitis, and joint exposure. (B) The wound healed with conservative treatment within 4 weeks.
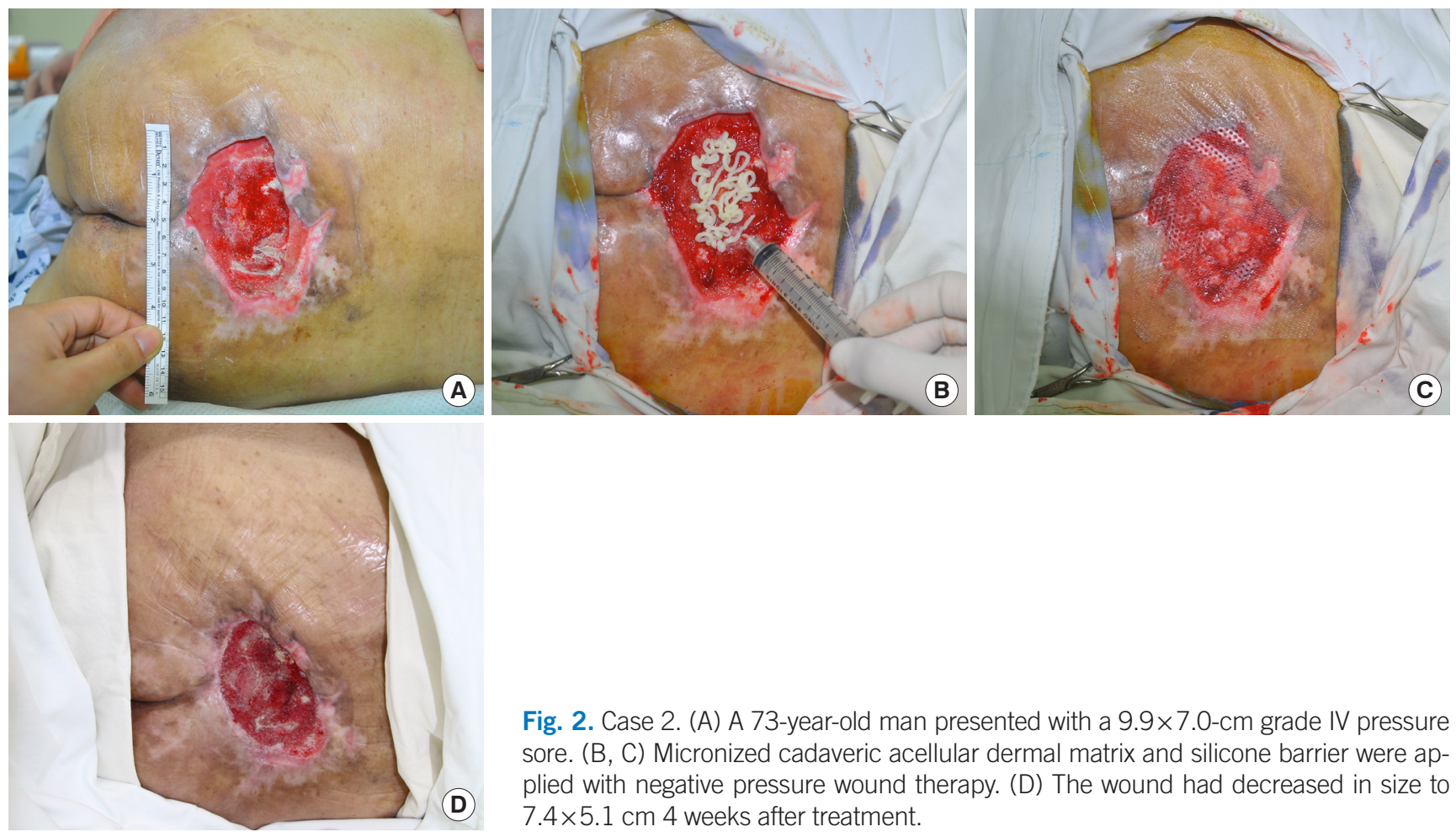

Fig. 2. Case 2. (A) A 73-year-old man presented with a $9.9 \times 7.0-\mathrm{cm}$ grade IV pressure sore. $(B, C)$ Micronized cadaveric acellular dermal matrix and silicone barrier were applied with negative pressure wound therapy. (D) The wound had decreased in size to $7.4 \times 5.1 \mathrm{~cm} 4$ weeks after treatment.

$\mathrm{mmHg}$ ) was then applied. The wound had decreased to $7.4 \times$ $5.1 \mathrm{~cm}$ after 4 weeks' treatment (Fig. 2). Wound depth also decreased from $15 \mathrm{~mm}$ to $6 \mathrm{~mm}$.

\section{Case 3}

A 54-year-old man presented with a venous stasis ulcer and a
$2.0 \times 2.0-\mathrm{cm}$ skin defect on his lower leg. The patient had edema and varicose veins, and the wound was covered with yellow fibrous tissue and infected discharge. Serial surgical debridement was performed until healthy granulation tissue on the wound was evident. mADM paste was then applied directly to the wound with a silicone barrier and NPWT. The wound 

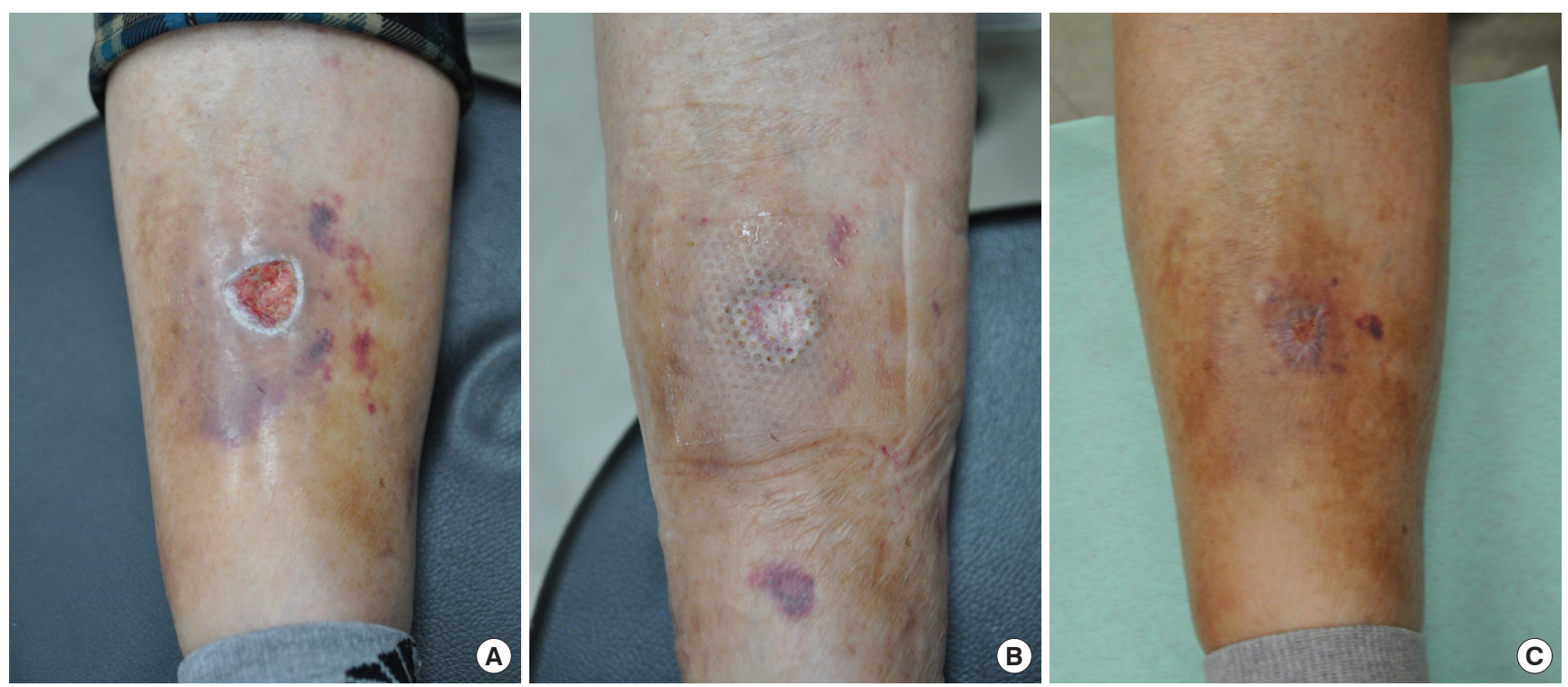

Fig. 3. Case 3. (A) A 54-year-old man presented with a venous static ulcer and 2.0×2.0-cm skin defect. (B) Micronized cadaveric acellular dermal matrix and silicone barrier were applied with negative pressure wound therapy. (C) The wound had decreased in size to $0.3 \times 0.3 \mathrm{~cm} 4$ weeks after treatment.
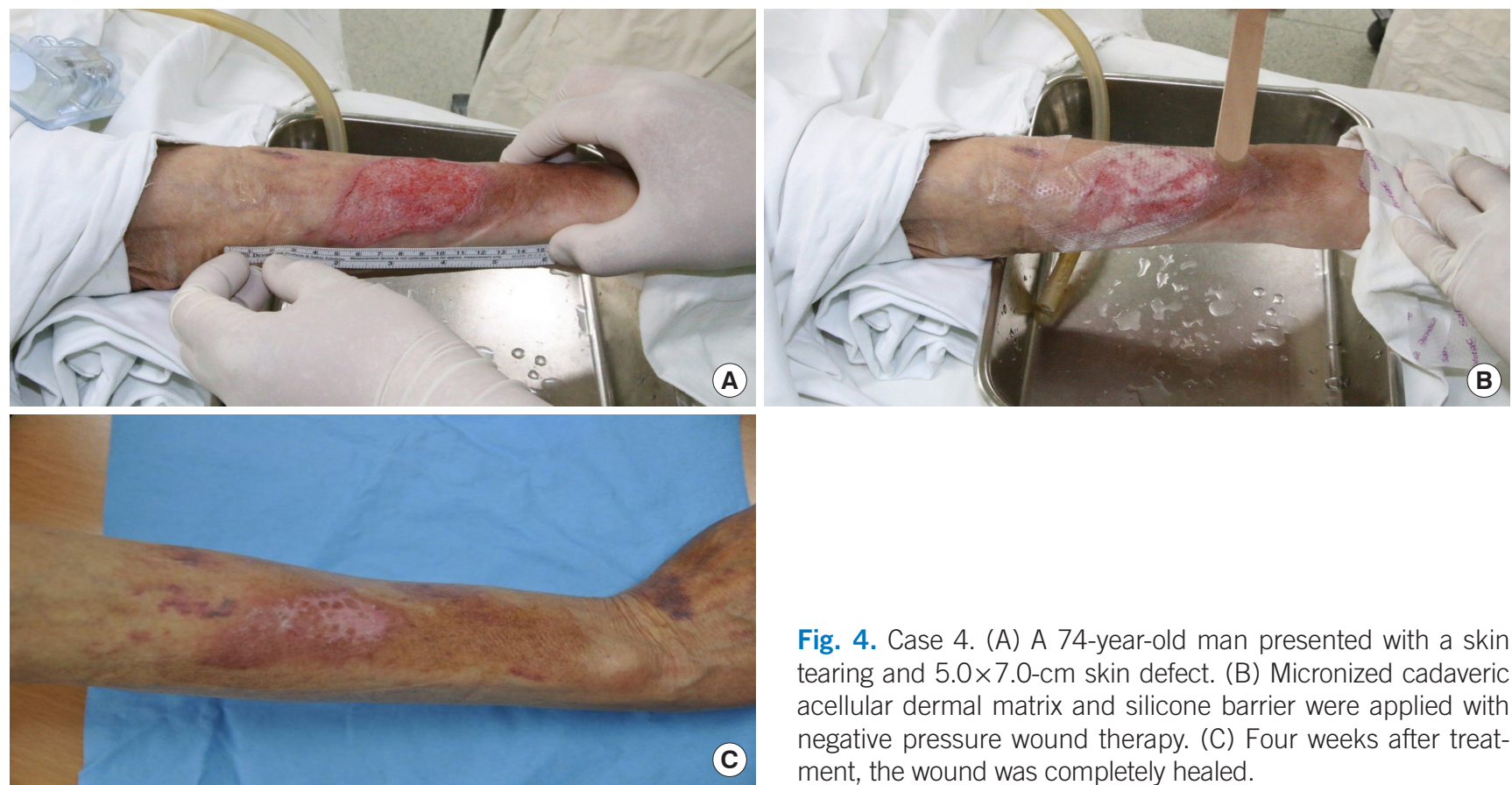

Fig. 4. Case 4. (A) A 74-year-old man presented with a skin tearing and 5.0 $07.0-\mathrm{cm}$ skin defect. (B) Micronized cadaveric acellular dermal matrix and silicone barrier were applied with negative pressure wound therapy. (C) Four weeks after treatment, the wound was completely healed.

had decreased to $0.3 \times 0.3 \mathrm{~cm} 4$ weeks after treatment (Fig. 3).

\section{Case 4}

A 74-year-old man presented with skin tearing and a 5.0 $\times 7.0$ $\mathrm{cm}$ skin defect, which was likely the result of iatrogenic Cushing syndrome. Four weeks after treatment with $\mathrm{mADM}$ paste and NPWT, the wound was completely healed (Fig. 4).

\section{Results}

Twenty participants were registered in this trial. The demographic information and clinical characteristics are shown in Table 1. Among the variables of the first effectiveness test, the mean area and depths of the wounds were observed to have decreased. The area of the wound was measured in all 20 study 
Table 1. Demographic characteristic and clinical materials $(n=20)$

\begin{tabular}{|c|c|}
\hline Characteristic & Value \\
\hline \multicolumn{2}{|l|}{ Age (yr) } \\
\hline Mean \pm SD & $61.50 \pm 13.18$ \\
\hline Median (range) & $57.50(44.00-82.00)$ \\
\hline \multicolumn{2}{|l|}{ Sex } \\
\hline Male & $14(70)$ \\
\hline Female & $6(30)$ \\
\hline \multicolumn{2}{|l|}{ Drinking } \\
\hline None & $14(70)$ \\
\hline Quit drinking (<3 mon) & $1(5)$ \\
\hline Quit drinking ( $\geq 3$ mon) & $1(5)$ \\
\hline Drinking & $4(20)$ \\
\hline \multicolumn{2}{|l|}{ Smoking } \\
\hline None & $13(65)$ \\
\hline Stopped smoking ( <3 mon) & 0 \\
\hline Stopped smoking ( $\geq 3$ mon) & $1(5)$ \\
\hline Smoking & $6(30)$ \\
\hline \multicolumn{2}{|l|}{ History } \\
\hline None & $1(5)$ \\
\hline Identified & $19(95)$ \\
\hline \multicolumn{2}{|l|}{ Medication } \\
\hline None & $3(15)$ \\
\hline Identified & $17(85)$ \\
\hline \multicolumn{2}{|l|}{ Physical examination } \\
\hline Normal & $13(65)$ \\
\hline Abnormal & $7(35)$ \\
\hline \multicolumn{2}{|l|}{ Hypertension } \\
\hline None & $9(45)$ \\
\hline Diagnosed & $11(55)$ \\
\hline \multicolumn{2}{|l|}{ Diabetes mellitus } \\
\hline None & $8(40)$ \\
\hline Diagnosed & $12(60)$ \\
\hline \multicolumn{2}{|l|}{ Wound location } \\
\hline Sacrum & $3(15)$ \\
\hline Upper extremity & $2(10)$ \\
\hline Lower extremity (except foot) & $5(25)$ \\
\hline Foot & $10(50)$ \\
\hline
\end{tabular}

Values are presented as number (\%).

participants, which decreased from an average of $15.48 \pm 22.38$ $\mathrm{cm}^{2}$ at the start of the study to $8.97 \pm 17.73 \mathrm{~cm}^{2}$ after 4 weeks, with a reduction rate of $59.10 \% \pm 31.76 \%(\mathrm{P}<0.0001)$.
In addition to the area of the wound, we also measured the vertical wound depth whenever possible. The wound depth was measured every week, and patients were excluded from the list when they had healed to a degree that rendered it impossible to measure the wound depth. At the start of the study, the depth of the wound was measurable and showed an average depth of $9.8 \pm 8.3 \mathrm{~mm}$ for 12 patients. The average of the measurable wound depth was obtained each week and the extent of change made was compared with the previous week, using Wilcoxon signed-rank test and paired t-test. Two weeks into the study, there was a significant decline in the wound depth compared with the previous week, and at 2, 3, and 4 weeks of the study, all statistical results were significant (Table 2).

The number and percentage of examinees were given by descriptive statistics among variables in the second effectiveness test. After 4 weeks' treatment, 13 of the 20 patients (65\%) had wound closure through secondary intention healing using only mADM paste with NPWT. In two patients, the wound beds were successfully prepared with healthy granulation tissue; thus, they were treated with skin graft or local flap coverage. Counting these two patients, a total of 15 patients (75\%) fully recovered within 4 weeks. Hematoma or seroma did not occur in any patient during the research period and re-operation was needed in one patient at approximately 1 to 2 weeks (Table 3).

Vital signs including blood pressure, pulse, temperature, and respiration rate were examined, and each time point was compared with baseline by paired t-test or Wilcoxon signedrank test. No difference was found at any time point compared to baseline.

The CRP level at each point was compared to baseline by paired t-test or Wilcoxon signed-rank test. The number of examinees and 95\% confidence intervals were given by classifying normal and abnormal CRP levels. There were no statistically significant changes.

No patients exhibited any adverse event related to the treatment. At the conclusion of the clinical trial, all patients were satisfied or very satisfied with the treatment.

\section{Discussion}

Wound healing involves interactions between cells and their micro-environment. The extracellular matrix (ECM) provides structural support for organs, tissues, cell layers (as basement membranes) and individual cells (as substrates for motility). ECM also has a significant role in cell adhesion and cell signal- 
Ahn SK et al.

mADM paste for hard to heal wound

Table 2. First effectiveness test: mean area of the wound and progress of decreasing depth

\begin{tabular}{|c|c|c|c|c|}
\hline & No. of patients & Mean \pm SD & Median (range) & P-value \\
\hline Wound area $\left(\mathrm{cm}^{2}\right)$ & & & & - \\
\hline Baseline (0 day) & 20 & $15.48 \pm 22.38$ & 5.98 (0.56 to 91.42) & \\
\hline Visit 5 (4 weeks) & 20 & $8.97 \pm 17.73$ & 2.56 (0.01 to 75.73$)$ & \\
\hline Reduction rate (visit 5-baseline) & 20 & $59.10 \pm 31.76$ & 61.81 (6.35 to 99.62) & $<0.0001^{\mathrm{b}}$ \\
\hline Wound depth (mm) & & & & - \\
\hline Baseline (0 day) & 12 & $9.8 \pm 8.3$ & 7.5 (1 to 30$)$ & \\
\hline Visit 2 (1 week) & 10 & $6.4 \pm 5.3$ & $4(2$ to 20) & \\
\hline Visit 3 (2 weeks) & 10 & $5.4 \pm 4.9$ & 3.5 (1.5 to 18) & \\
\hline Visit 4 (3 weeks) & 9 & $2.2 \pm 2.7$ & $2(0$ to 8$)$ & \\
\hline Visit 5 (4 weeks) & 5 & $4.4 \pm 4.3$ & $2(0$ to 10$)$ & \\
\hline Difference (visit 2-baseline) & 10 & $-0.90 \pm 1.73$ & $-1(-3$ to 3$)$ & 0.1341 \\
\hline Difference (visit 3-baseline) & 10 & $-1.85 \pm 1.92$ & -1.75 (-5 to 2) & $0.0137^{b}$ \\
\hline Difference (visit 4-baseline) & 9 & $-7.56 \pm 9.13$ & $-3(-25$ to 2$)$ & $0.0156^{b}$ \\
\hline Difference (visit 5-baseline) & 5 & $-2.60 \pm 1.52$ & $-2(-5$ to -1$)$ & $0.0186^{b}$ \\
\hline
\end{tabular}

a) Result of the Wilcoxon signed-rank test or paired t-test for result comparison from the contrasted baseline for each test time; ${ }^{\text {bl }} \mathrm{P}<0.05$.

Table 3. Second effectiveness test: rate of occurrence of infection, hematoma, occurrence of seroma, and reoperation

\begin{tabular}{llc}
\hline Infection incidence & No. (\%) & 95\% Confidence interval \\
\hline Baseline (0 day) & 0 & $0.00-16.84$ \\
Visit 2 ( 1 week) & 0 & $0.00-16.84$ \\
Visit 3 (2 weeks) & 0 & $0.00-17.65$ \\
Visit 4 (3 weeks) & 0 & $0.00-21.16$ \\
Visit 5 (4 weeks) & 0 & $0.00-33.63$ \\
Hematoma, seroma incidence & & \\
Visit 2 ( 1 week) & 0 & $0.00-16.84$ \\
Visit 3 (2 weeks) & 0 & $0.00-17.65$ \\
Visit 4 (3 weeks) & 0 & $0.00-21.16$ \\
Visit 5 (4 weeks) & 0 & $0.00-33.63$ \\
Reoperation rate & & \\
Visit 2 ( 1 week) & 0 & $0.00-16.84$ \\
Visit 3 (2 weeks) & 1 (5.26) & $0.13-26.03$ \\
Visit 4 (3 weeks) & 0 & $0.00-21.16$ \\
Visit 5 (4 weeks) & 0 & $0.00-33.63$ \\
\hline
\end{tabular}

ing through adhesion receptors including integrins [5-7]. Moreover, mechanical characteristics of the matrix such as stiffness and deformability provide inputs into cell behavior $[8,9]$. Therefore, it is clear that ECM proteins and structures play an important role in cell determination, differentiation, diffusion, survival, polarity, and migration. The application of acellular dermal matrix (ADM) is rising as a useful substitute for the ECM in chronic wounds $[10,11]$. When applied to a wound, ADMs provide an intact framework that acts as a scaffolding of biological components (such as collagen, elastin and fibronectin) for ingrowth of the patient's cells, allowing the body to initiate a self-tissue regeneration process, while also retaining the ECM's role in cell adhesion and cell signaling.

Conventional ADM products have disadvantages, such as high cost and inability to fit in irregularly contoured wounds. To overcome these issues, we used mADM. Compared to conventional $\mathrm{ADM}, \mathrm{mADM}$ can be used for less than half the price to cover a wound of the same volume.

The mADM paste used in this study is CG Paste which is manufactured by mixing with a gelatin suspension. Gelatin is a protein biopolymer derived from native collagen, which is a structural protein that occupies the most part of the human skin, tendon, cartilage, and bone. Gelatin has several advantages such as biological origin, non-immunogenicity, biodegradability, biocompatibility, and relatively low cost [12]. In this study, NPWT was used together to enhance the effectiveness of mADM. The use of negative pressure to promote wound healing has increased in popularity in the past decade, and we also have obtained good results in the healing of complex wounds using NPWT.

Strangely, few randomized clinical trials have been performed to investigate the digitized comparisons of NPWT and modern wound dressings. One study randomized 32 patients to vacuum-assisted closure therapy with the modern dressing 
group being the control group. Jones et al. [13] used NPWT and observed that the wound healing was at least as fast as that with modern wound dressings. The total costs of NPWT are comparable to those of modern wound dressings, but the advantage is its comfort for patients and the medical staff [14]. Another study retrospectively reviewed the charts of 20 patients with infected wounds treated using NPWT. The use of the NPWT led to a mean reduction of $29 \%$ in the wound area after 42 days (range, $95.65-68.1 \mathrm{~cm}^{2}$; $\mathrm{P}<0.05$ ) [13]. In a previous study, we applied NPWT to pressure ulcers for 1 month, and observed $-18.08 \% \pm 31.32 \%$ and $-4.28 \pm 8.83 \mathrm{~cm}^{2}$ area change [15]. Despite the severity of wounds in patients in our present study, mADM with NPWT resulted in significantly better healing time.

There has not been much progress yet in the study of $\mathrm{mADM}$, and some case reports have been reported, but no randomized and prospective research has yet been applied to the use of $\mathrm{mADM}$ in chronic wounds. Jeon and Kim [16] perform a retrospective study which applied mADM to chronic wounds, and healing was achieved in an average period of 2.4 weeks in five out of seven people. We also have experience in using $\mathrm{mADM}$ in other studies to complete healing chronic wound caused by silicone injection [17]. On these bases, we believed $\mathrm{mADM}$ paste would promote rapid revascularization and cellular repopulation of the matrix scaffold even in patients who had bone or tendon exposure, achieving a proper granulation tissue bed for skin grafting.

Another very important advantage of $\mathrm{mADM}$ with NPWT is that, just as with NPWT, it involves minimal discomfort for the patient and relative ease for the treating team of physicians and nursing staff. Dressings do not need to be changed as frequent as other conventional dressings, and minimal or none odor and fluid leakage occurs with NPWT. The paste-type mADM is also very easy to apply and contour to complex wound surfaces, requiring only a few seconds.

In this study, we applied NPWT with controlled continuous or intermittent pressure. A recent trend is to maintain low pressure on the wound to prevent poor circulation. We also carefully observe wounds for signs of compromised circulation during every change of NPWT.

The main drawback of this study is that it did not able to compare the effects of mADM paste used together with NPWT with those of using only NPWT or only mADM. Further research will be needed in these aspects. Our use of mADM paste with NPWT decreased the size of even very large wounds, but not all of the mADM paste applied was suc- cessfully integrated into the wounds, and residual material did fall out during dressing changes. To compensate for this, research will be necessary to determine the appropriate amount of mADM paste to apply to wounds in order to reduce waste.

Our results show that mADM with NPWT provides effective wound healing in hard-to-heal wounds. It is more comfortable for patients and less time-consuming for the medical staff; thus, this treatment deserves a prominent place in the care of hard-to-heal wound patients.

\section{Conflict of interest}

No potential conflicts of interest relevant to this article are reported.

\section{Acknowledgments}

Seung Ki Ahn https://orcid.org/0000-0002-0458-3800

Hwan Jun Choi https://orcid.org/0000-0002-0752-0389

\section{References}

1. Fleischmann W, Becker U, Bischoff M, et al. Vacuum sealing: indication, technique, and results. Eur J Orthop Surg Traumatol 1995;5:37-40.

2. Maloney BP, Murphy BA, Cole HP 3rd. Cymetra. Facial Plast Surg 2004;20:129-34.

3. Troxler M, Vowden K, Vowden P. Integrating adjunctive therapy into practice: the importance of recognising "hard-to-heal' wounds [Internet]. World Wide Wounds; c2006 [cited 2019 Feb 23]. Available from: http://www.worldwidewounds. com/2006/december/Troxler/Integrating-Adjunctive-Therapy-Into-Practice.html.

4. Bulstrode CJ, Goode AW, Scott PJ. Stereophotogrammetry for measuring rates of cutaneous healing: a comparison with conventional techniques. Clin Sci (Lond) 1986;71:437-43.

5. Hynes RO. Integrins: bidirectional, allosteric signaling machines. Cell 2002;110:673-87.

6. Berrier AL, Yamada KM. Cell-matrix adhesion. J Cell Physiol 2007;213:565-73.

7. Legate KR, Wickstrom SA, Fassler R. Genetic and cell biological analysis of integrin outside-in signaling. Genes Dev 2009;23:397-418.

8. Discher DE, Mooney DJ, Zandstra PW. Growth factors, matrices, and forces combine and control stem cells. Science 2009;324:1673-7. 
9. Geiger B, Spatz JP, Bershadsky AD. Environmental sensing through focal adhesions. Nat Rev Mol Cell Biol 2009;10:2133.

10. Kirsner RS, Bohn G, Driver VR, et al. Human acellular dermal wound matrix: evidence and experience. Int Wound J 2015;12:646-54.

11. Cazzell S, Vayser D, Pham H, et al. A randomized clinical trial of a human acellular dermal matrix demonstrated superior healing rates for chronic diabetic foot ulcers over conventional care and an active acellular dermal matrix comparator. Wound Repair Regen 2017;25:483-97.

12. Zhang YZ, Venugopal J, Huang ZM, et al. Crosslinking of the electrospun gelatin nanofibers. Polymer 2006;47:2911-7.

13. Jones DA, Neves Filho WV, Guimaraes JS, et al. The use of negative pressure wound therapy in the treatment of infected wounds. Case studies. Rev Bras Ortop 2016;51:646-51.
14. Braakenburg A, Obdeijn MC, Feitz R, et al. The clinical efficacy and cost effectiveness of the vacuum-assisted closure technique in the management of acute and chronic wounds: a randomized controlled trial. Plast Reconstr Surg 2006;118: 390-7.

15. Ahn SK, Choi HJ, Kim JK, et al. Clinical effects of negative pressure wound therapy and basic fibroblast growth factor in patients with pressure ulcers. J Wound Management Res 2018;14:18-25.

16. Jeon M, Kim SY. Application of a paste-type acellular dermal matrix for coverage of chronic ulcerative wounds. Arch Plast Surg 2018;45:564-71.

17. Ahn SK, Choi HJ, Jang SH. Rare complication of silicone fluid injection in lower leg cared by micronized acellular dermal matrix. J Wound Management Res 2018;14:107-11. 